OPEN Mechanism of Action of

SUBJECT AREAS:

PROTEOMICS

ENZYME MECHANISMS

Received

17 October 2014

Accepted

4 February 2015

Published

5 March 2015

Correspondence and requests for materials should be addressed to

P.-Y.Q. (boqianpy@

ust.hk); B.S.M.

(bsmoore@ucsd.edu) or Y.X. (boxuying@ szu.edu.cn)

\title{
Thalassospiramides, A New Class of Calpain Inhibitors
}

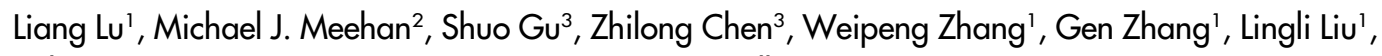
Xuhui Huang ${ }^{3}$, Pieter C. Dorrestein ${ }^{2,4,5}$, Ying Xu ${ }^{1,6}$, Bradley S. Moore ${ }^{2,5}$ \& Pei-Yuan Qian'

'KAUST Global Collaborative Research, Division of Life Science, School of Science, Hong Kong University of Science and Technology, Clear Water Bay, Hong Kong, China, ${ }^{2}$ Skaggs School of Pharmacy \& Pharmaceutical Sciences, University of California at San Diego, La Jolla, California 92037, United States, ${ }^{3}$ Department of Chemistry, Hong Kong University of Science and Technology, Clear Water Bay, Hong Kong, China, ${ }^{4}$ Department of Pharmacology, University of California at San Diego, La Jolla, California 92037, United States, ${ }^{5}$ Center for Marine Biotechnology and Biomedicine, Scripps Institution of Oceanography, University of California at San Diego, La Jolla, California 92037, United States, ${ }^{6}$ School of Life Science, Shenzhen University, Nanhai Ave 3688, Shenzhen, Guangdong Province, 518060, China.

Thalassospiramides comprise a large family of lipopeptide natural products produced by Thalassospira and Tistrella marine bacteria. Here we provide further evidence of their nanomolar inhibitory activity against the human calpain 1 protease. Analysis of structure-activity relationship data supported our hypothesis that the rigid 12-membered ring containing an $\alpha, \beta$-unsaturated carbonyl moiety is the pharmacologically active functional group, in contrast to classic electrophilic "warheads" in known calpain inhibitors. Using a combination of chemical modifications, mass spectrometric techniques, site-directed mutagenesis, and molecular modeling, we show the covalent binding of thalassospiramide's $\alpha, \beta$-unsaturated carbonyl moiety to the thiol group of calpain's catalytic Cys115 residue by a Michael 1,4-addition reaction. As nanomolar calpain inhibitors with promising selectivity and low toxicity from natural sources are rare, we consider thalassospiramides as promising drug leads.

\footnotetext{
alpain is a calcium-dependent cysteine protease that participates in many signal transduction events by catalyzing the proteolysis of specific peptides in target substrates ${ }^{1-3}$. Deregulation of calpain action has been identified in pathologies such as neurological disorders, muscular dystrophies, cortical cataracts, cancer, and inflammation ${ }^{4-9}$. To date, more than 200 calpain inhibitors have been reported with most being synthetic peptides and peptidomimetics that target active site residues ${ }^{10}$. A common feature of these inhibitors is the presence of a classical electrophilic warhead (e.g., aldehyde, $\alpha$-ketocarbonyl, and epoxysuccinyl) to interact with the active site cysteine residue (Cys115) of calpain ${ }^{11-13}$. However, major hindrances in the clinical application of these classical inhibitors are their poor selectivity for calpain, tendency to interact with other cysteine proteases, and high potential for toxicity ${ }^{14-16}$.

Recently, we characterized 14 new and 2 known thalassospiramide lipopeptides from several Thalassospira and Tistrella marine bacterial species (see Fig. 1) and revealed their novel biosynthetic pathways ${ }^{17}$. Among these analogues, six were evaluated for their potent inhibitory activity against human calpain 1 protease (HCAN1). Although differences in bioactivity were as large as 20 -fold, all tested thalassospiramides were active at nanomolar concentrations, which suggests they are thus far the most potent calpain inhibitors retrieved from natural sources $^{13,14}$. Interestingly, the lack of the classical warhead and the presence of a common 12-membered ring system suggest that thalassospiramides may represent a new class of calpain inhibitors.
}

\section{Results}

Bioassay and Chemical Modifications. We accumulated all previously reported thalassospiramide analogues and evaluated their calpain 1 inhibitory activity using a fluorescence-based assay. The result showed that all thalassospiramides possessed nanomolar-level inhibitory activity against human calpain 1 (see Table 1), which suggests that the conserved 12-membered ring system with its electrophilic, unsaturated amide group might be the pharmacologically active moiety. To test this hypothesis, thalassospiramide A (1) was hydrolyzed at the ester position to 2 as well as hydrogenated at the double bond to 3 (see Fig. 2). In both cases, the products were 100-fold 

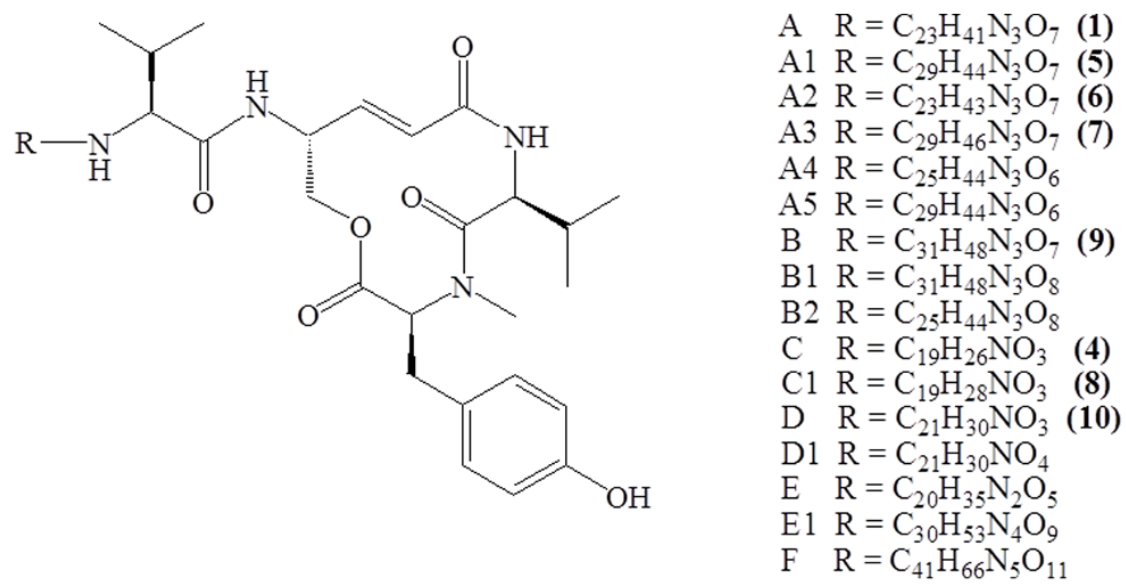

Figure 1 Chemical structure of thalassospiramide analogues. All thalassospiramides share a rigid 12-membered ring and a variable lipopeptide side chain (R). See Ross et al. ${ }^{17}$ for full structures.

less active in the calpain inhibitory assay, strongly indicating that the intact 12-membered ring system is a critical element for the inhibitory activity. Reduction of 1 to 3 also resulted in the saturation of the acyl side chain, which, based on natural thalassospiramide analogues in the series, does not significantly influence the overall calpain bioactivity (see Table 1). These results supported our hypothesis that the $\alpha, \beta$-unsaturated carbonyl moiety in the 12 membered ring system is essential for the inhibitory activity of calpain. We therefore predicted that Cys115 of calpain attacks the double bond of the unsaturated amide via a Michael-type 1,4addition to form a covalent linkage between the inhibitor and protein. A similar binding mechanism was reported between the active site Thr1 residue of the $20 \mathrm{~S}$ proteasome and the bacterial natural product syringolin $\mathrm{A}$, a potent proteasome inhibitor that also contains an $\alpha, \beta$-unsaturated amide in a 12 -membered ring system ${ }^{18}$.

Human Calpain 1 Sample Analysis by MALDI-TOF MS. Topdown and bottom-up mass spectrometry analyses were next used to explore this postulated mode of action ${ }^{19-22}$. Excess 1 and 3 were added to HCAN1 and incubated separately before being subjected to MALDI-TOF analysis. The results revealed that $1(957.5 \mathrm{Da})$ formed a covalent adduct with calpain, as the $\mathrm{m} / \mathrm{z}$ value was shifted by approximately $974 \mathrm{Da}$ in comparison to the control sample of "free" HCAN1 (see Fig. 3A). We measured only a 1:1 (HCAN1 to 1) complex despite using excessive amounts of 1 , suggesting a specific interaction between HCAN1 and 1. Conversely, the HCAN1 + 3 complex did not yield a significant mass shift (see Fig. 3A), as

Table 1 | Inhibitory activity of thalassospiramides against HCAN1

\section{Compound}

Thalassospiramide A (1)

Thalassospiramide A1 (5)

Thalassospiramide A2 (6)

Thalassospiramide A3 (7)

Thalassospiramide A4

Thalassospiramide A5

Thalassospiramide B (9)

Thalassospiramide B 1

Thalassospiramide B2

Thalassospiramide $C(\mathbf{4})$

Thalassospiramide $\mathrm{C} 1$ (8)

Thalassospiramide D (10)

Thalassospiramide D1

Thalassospiramide $\mathrm{E}$

Thalassospiramide E 1

Thalassospiramide $F$ anticipated, which is consistent with the loss of the electrophilic olefin in the 12-membered ring of 1 . These findings support the specific binding of 1 to just a single calpain amino acid residue.

To explore the nature of the covalent linkage between thalassospiramide and calpain, we digested three samples (free HCAN1, HCAN1 + 1, and HCAN1 + 3) with trypsin and analyzed the products by MALDI-TOF/TOF MS. The results revealed that the Cys115-containing peptide fragment TDICQGALGDC ${ }_{115}$ WLLAA- $^{-}$ IASLTLNDTLLHR (cal. $m / z=3097.6$ ) could be detected in the free HCAN1 and HCAN1 +3 samples but not in the HCAN1 $+\mathbf{1}$ sample (see Fig. 3B and Supplementary Fig. 1) in support of the proposed mechanism. Unfortunately, using MALDI-TOF we were unable to detect the anticipated tryptic peptide fragment with $1(\mathrm{~m} / z$ $=4055.1)^{23,24}$.

Protein Mutation, Expression, and Identification. Our previous MALDI-TOF MS result showed that only one molecule of 1 binds per calpain (see Fig. 3A), which indicates that the interaction between calpain and thalassospiramide is highly specific. If Cys115 is the specific attachment site, then a Cys115-mutant calpain should not form a covalent bond with 1 and therefore no mass shift should be observed. To test this hypothesis, the protease core of human calpain 1 (domains I-II of $\mu$-calpain, " $\mu I$-II" as abbreviation), which retains the functional and structural elements of intact calpain ${ }^{25}$, was mutated to replace the Cys 115 active site residue with Ala ( $\mu$ I-IIC115A). Native and mutated $\mu \mathrm{I}$-II proteins were expressed, purified and their sequences verified (see Supplementary Fig. 3, 4 and 5). However, the calculated and observed masses of the two proteins, as measured by FT-ICR-MS, were in discordance ( $\mu \mathrm{I}-\mathrm{II}$, cal. exact mass: $42239.9 \mathrm{Da}$, obs. exact mass: 42467.9 Da; $\mu$ I-IIC115A, cal. Exact mass: 42207.9 Da, obs. exact mass: $42360.1 \mathrm{Da})$. Considering that the observed mass deviations of $\mu \mathrm{I}-\mathrm{II}$ and $\mu \mathrm{I}-\mathrm{IIC} 115 \mathrm{~A}$ were 228 and $152 \mathrm{amu}$, respectively, and that both are multiples of 76 , we reasoned that these differences were most likely due to the addition of $\beta$ mercaptoethanol $(\beta-\mathrm{ME}, 76.0 \mathrm{Da})$ from the storage buffer ${ }^{26}$. In order to verify that the observed mass deviations of the intact protein were actually caused by $\beta$-ME adducts, we performed a brief (30 minute) trypsin digestion of $\mu \mathrm{I}-\mathrm{II}$, to be followed by MS analysis, without the use of additional reducing agents such as TCEP $^{27}$. HPLC fractionation and MS/MS analysis of the resulting peptides showed that three of the five cysteine residues were modified by $\beta$-ME (cys49, cys108 and Cys115; see Supplementary Fig. 6). This is consistent with the crystal structure of $\mu \mathrm{I}-\mathrm{II}^{28}$ (PDB file: $1 \mathrm{ZCM}$ ) in which only these three cysteine residues reside on the solvent-accessible surface of the protein. Verification of the formation of these $\beta$-ME adducts clearly explained the observed 


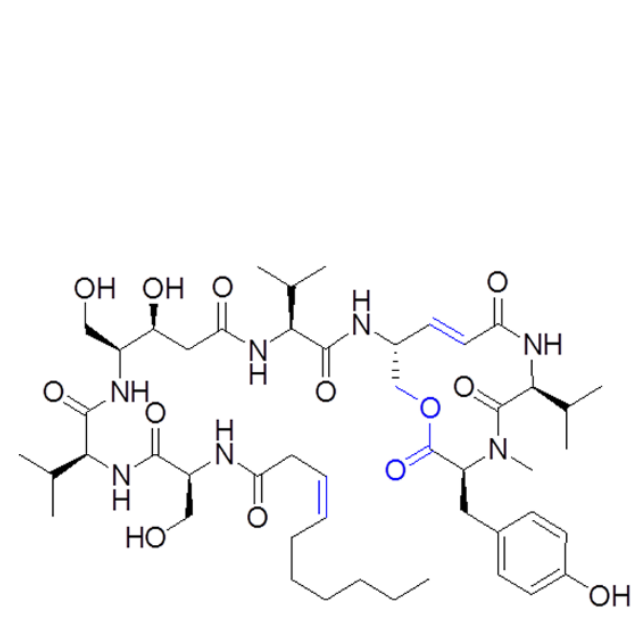

$1 \mathrm{IC}_{50}=\mathbf{4 6} \mathrm{nM}$

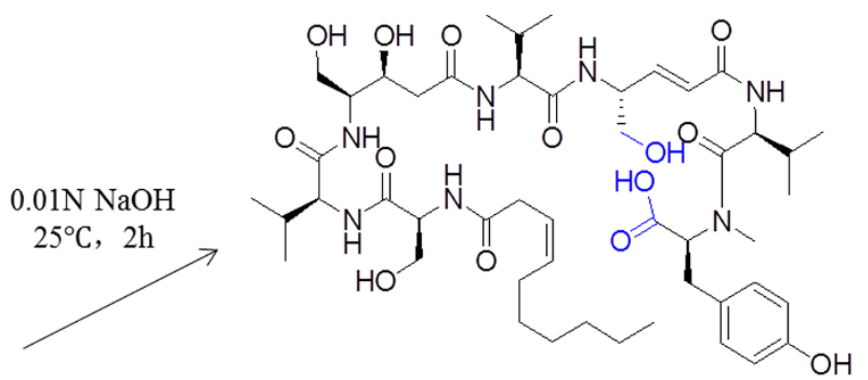

$2 \mathrm{IC}_{50}>\mathbf{5 0 0 0} \mathrm{nM}$

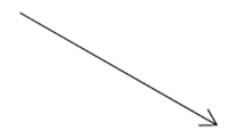

$10 \% \mathrm{Pd} / \mathrm{C}, \mathrm{H}_{2}$ $25^{\circ} \mathrm{C}, 5 \mathrm{~h}$

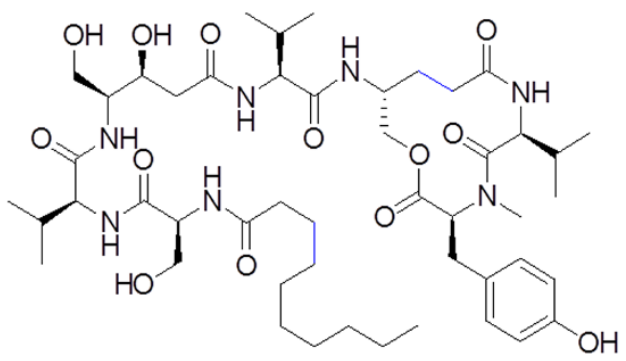

$3 \mathrm{IC}_{50}>\mathbf{5 0 0 0} \mathrm{nM}$

Figure $2 \mid$ Chemical modifications of 1 and the comparison of IC $_{50}$ values against HCAN1. Both modifications (ester hydrolysis to 2 and double-bond saturation to 3 ) led to loss of bioactivity.

masses for both $\mu \mathrm{I}-\mathrm{II}(+228 \mathrm{Da}, 3 \mathrm{x} \beta-\mathrm{ME})$ and $\mu \mathrm{I}-\mathrm{IIC} 115 \mathrm{~A}$ $(+152 \mathrm{Da}, 2 \mathrm{x} \beta-\mathrm{ME})$.

Expressed Protein Sample Analysis by FT-ICR and Q-TOF MS. We next incubated excess 1 with $\mu \mathrm{I}-\mathrm{II}$ and $\mu \mathrm{I}$-IIC115A, purified the samples by C4 RP-HPLC, and analyzed them by FT-ICR-MS. HPLC chromatograms showed that the retention time of $\mu \mathrm{I}-\mathrm{II}$ was changed by $0.3 \mathrm{~min}$ following the addition of 1 and a shift of $+881.5 \mathrm{amu}$ was clearly measured by MS (see Fig. 4 and Fig. 5). This mass shift represents the displacement of $\beta$-ME (loss of $76 \mathrm{Da}$ ) from Cys115 and the subsequent addition of $\mathbf{1}$ (addition of $957.5 \mathrm{Da}$ ) in its place. On the contrary, neither a change of HPLC retention time nor a mass shift in the MS signal was found for the $\mu \mathrm{I}-\mathrm{IIC} 115 \mathrm{~A}$ sample after the addition of 1 (see Fig. 4 and Fig. 5). These results clearly signify that 1 interacts specifically with the Cys 115 residue. As additional confirmation of these results, both $\mu \mathrm{I}-\mathrm{II}+1$ and $\mu \mathrm{I}-\mathrm{IIC} 115 \mathrm{~A}+1 \mathrm{sam}$ ples were digested overnight with trypsin and analyzed by LC-MS/ MS (qTOF), which allowed the detection of the 1-modified fragment in the $\mu \mathrm{I}-\mathrm{II}+1$ sample (see Fig. 6 and Supplementary Fig. 8 ) and not the $\mu \mathrm{I}-\mathrm{IIC} 115 \mathrm{~A}+1$ sample. Based on these complimentary results, we conclude that thalassospiramide is exclusively associated with the Cys115 residue of calpain by a 1, 4 -addition reaction.

Molecular Modeling Study. To gain further insight into the binding properties between thalassospiramide analogues and calpain, we performed large-scale docking between various thalassospiramides and 30 representative calpain conformations (PDB file: 1ZCM) generated via molecular dynamics simulations. Our docking results showed that thalassospiramide C (4), which experimentally demonstrated the greatest potency, reached Cys 115 over the shortest distance, had the lowest docking energy of $-8.1 \mathrm{kcal} / \mathrm{mol}$, and experienced the largest number of binding conformations with a distance of less than $5 \AA$ (see Supplementary Table 1 and Supplementary Fig. 9). Moreover, 4 had the shortest lipopeptide side chain that enables tight interaction with the three important regions of calpain (S1, S2, and S3) ${ }^{14}$, which is consistent with our previous observations of markedly different bioactivities associated with the variable hydrophobic tails in the thalassospiramide series. In the case of syringolin A, which shares a similar ring structure to 4 , Clerc et al. found that its proteasome inhibitory activity was enhanced more than 100 -fold by modifications to the side chain ${ }^{29}$. Furthermore, the nucleophilic attack of Cys115 leads to the S-configuration of the resulting chiral center, the same as the study of Cysteine Cathepsins ${ }^{30}$.

Preliminary Selectivity and Toxicity Studies. Thalassospiramides 1 and 4 were inactive against the human $20 \mathrm{~S}$ proteasome at $10 \mu \mathrm{M}$, and have been reported to have weak activity against papain and none against trypsin ${ }^{31,32}$. In a preliminary toxicity study, we did not observe any obvious growth inhibition against the bacterial strains Staphylococcus aureus, the fungal strain Candida albicans, and $\mathrm{HeLa}$ cells with $10 \mu \mathrm{M} 1$ and 4-8. In addition, Oh et al. reported that at a concentration of $10 \mu \mathrm{M}$ of either 1 or 9 or $20 \mu \mathrm{M}$ of 10 , no cytotoxicity was observed in a mouse model ${ }^{33}$. These preliminary findings suggest that thalassospiramide may possess both low toxicity and good selectivity.

\section{Discussion}

We report that thalassospiramide natural products are potent inhibitors of calpain and function differently from standard calpain inhibitors. Most inhibitors possess highly reactive aldehyde groups that bind covalently to the active site of calpain, causing disadvantages such as non-selectivity, instability, and excessive metabolism ${ }^{34-37}$. Although other examples of $\alpha, \beta$-unsaturated amides have been reported as electrophilic inhibitors of cysteine proteases ${ }^{38-40}$, this is the first report that an $\alpha, \beta$-unsaturated carbonyl moiety in a rigid ring system functions as an electrophilic warhead at nanomolar scale inhibitory activity against calpain. Interestingly, our previous biosynthetic study revealed that despite the great variety of side chains amongst the 16 known thalassospiramide analogues, the 12 -membered macrolide ring is perfectly conserved ${ }^{17}$. These observations 
Free HCAN1
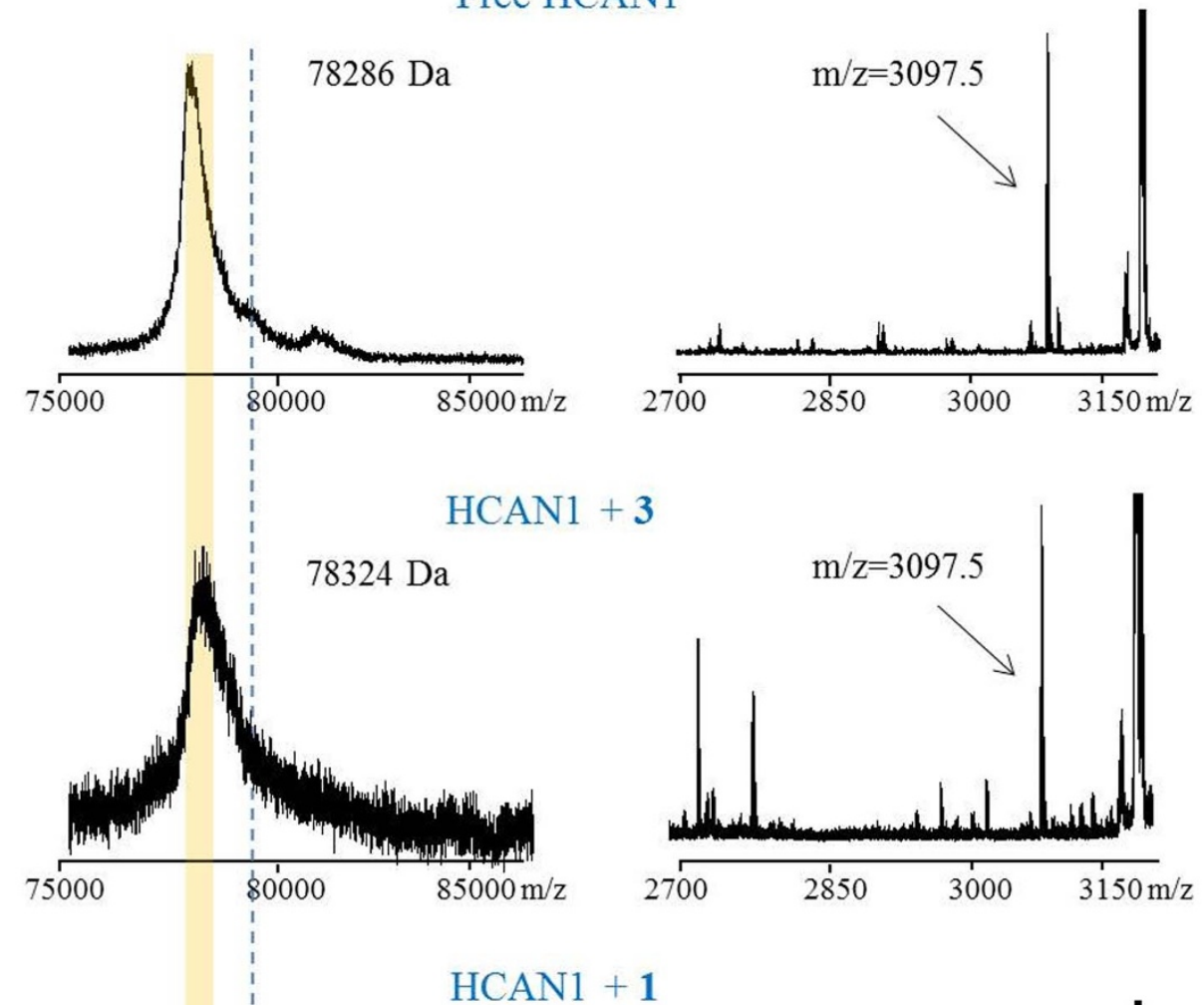

$79260 \mathrm{Da}$
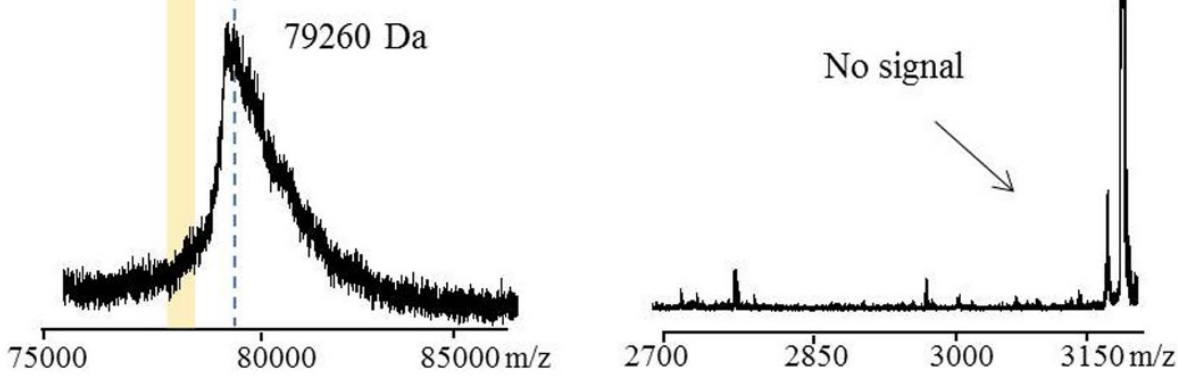

Figure 3 MALDI-TOF MS analysis of calpain samples. A) Intact protein analysis of free HCAN1, HCAN1 + $\mathbf{3}$ and HCAN1 $+\mathbf{1}$ samples. Compared with free HCAN1, an obvious shift could be detected in the HCAN1 + 1 sample, which has a molecular weight similar to 1 (957.5 Da). B) Analysis of the three samples after trypsin digestion. Signal of original peptide $(m / z=3097.5)$ completely disappeared in the HCAN1 +1 sample.

suggest that this core structure may possess important physiological function(s) and could serve as a new scaffold for drug design.

\section{Methods}

Fluorescence-based Calpain Activity Assay. Calpain 1 activity was measured according to the protocol provided with the Calpain Activity Assay Kit (K240-100, BioVision, USA). Tested compounds were dissolved in DMSO and serially diluted in methanol to obtain various concentrations (600 nM, $125 \mathrm{nM}, 25 \mathrm{nM}, 5 \mathrm{nM}, 1 \mathrm{nM})$ The calpain inhibition assays were performed in 96 -well plates. Each assay was initiated by combining $85 \mu \mathrm{L}$ extraction buffer and 0.1 U HCAN1 (BioVision, USA). Subsequently, $1 \mu \mathrm{L}$ test compound of the desired concentration, $10 \mu \mathrm{L}$ reaction buffer, and $5 \mu \mathrm{L}$ calpain substrate (Ac-LLY-AFC) was added to each well. The plate was incubated at $37^{\circ} \mathrm{C}$ for $1 \mathrm{~h}$ in the dark. The test samples were then recorded using a fluorometer equipped with an excitation wavelength of $400 \mathrm{~nm}$ and an emission wavelength of $505 \mathrm{~nm}$. Samples without HCAN1 or test compound were defined as blank controls, and samples without test compounds were defined as negative controls. The reported $\mathrm{IC}_{50}$ values are the average of triplicate determinations.

Preparation of Compounds. All thalassospiramides in this study were obtained from the marine bacteria Thalassospira sp. CNJ328 and Tistrella bauzanensis TIO7329 ${ }^{17}$. Compounds were purified using RP HPLC (Luna $5 \mu \mathrm{C}_{18}$ (2), $250 \times 1.00 \mathrm{~mm}, 100 \AA$, Phenomenex, Torrance CA) and analyzed using UPLC-ESI-HRMS $\left(1.7 \mu \mathrm{m} \mathrm{C}_{18}\right.$ column, $0.25 \mathrm{~mL} / \mathrm{min}$, gradient from $5 \%$ to $95 \% \mathrm{CH}_{3} \mathrm{CN}$ with $0.1 \%$ TFA, $25 \mathrm{~min}$ ). The NMR spectra were obtained using a Varian Inova $500 \mathrm{MHz}$ spectrometer. All samples were dissolved in $\mathrm{MeOH}-d_{4}$, and chemical shifts were reported in ppm relative to TMS. The ESI-HRMS analysis was conducted using a Bruker Daltonics micrOTOF instrument (Bruker Daltonics GmbH, Bremen, German). The procedures of chemical modifications of 1 were described: (a) Ester hydrolysis of 12-membered ring of 1 . Compound $1(1 \mathrm{mg})$ was dissolved in $3 \mathrm{~mL}$ water solution $(0.01 \mathrm{~N} \mathrm{NaOH}$, $50 \%$ methanol) and stirred for 2 hour at room temperature. After the reaction, the sample was neutralized and the solution was evaporated in vacuo. The product 2 $(0.6 \mathrm{mg})$ was dissolved in $\mathrm{MeOH}$ and purified using RP-HPLC with an isocratic method of $45 \% \mathrm{CH}_{3} \mathrm{CN}$ in water. (b) Hydrogenation of double bond of 1 . Compound 1 was dissolved in ethanol and stirred for 5 hour together with $10 \% \mathrm{Pd} / \mathrm{C}$ catalyst under atmospheric $\mathrm{H}_{2}$ at room temperature. The catalyst was blocked with $0.25-\mu \mathrm{m}$ filter membrane and the solvent was removed in vacuo. The reaction product was confirmed by an increased molecular weight of 4 daltons and MS/MS annotation by LC/MS analysis.

MALDI-TOF Mass Spectrometry Analysis. For sample preparation, the C4 Zip Tip (Millipore) was used for desalting and purification by washing with $20 \%$ acetonitrile water solution $(0.1 \%$ TFA). Protein samples were eluted with $60 \%$ acetonitrile water solution $(0.1 \%$ TFA) and dried under a stream of nitrogen. Treated proteins were dissolved in a saturated sinapinic acid (SA) matrix solution and applied to the MALDI ground steel plate (Bruker Daltonics). After air drying, the samples were analyzed in linear mode using an ultrafleXtreme MALDI-TOF-MS (Bruker Daltonics, Germany). 


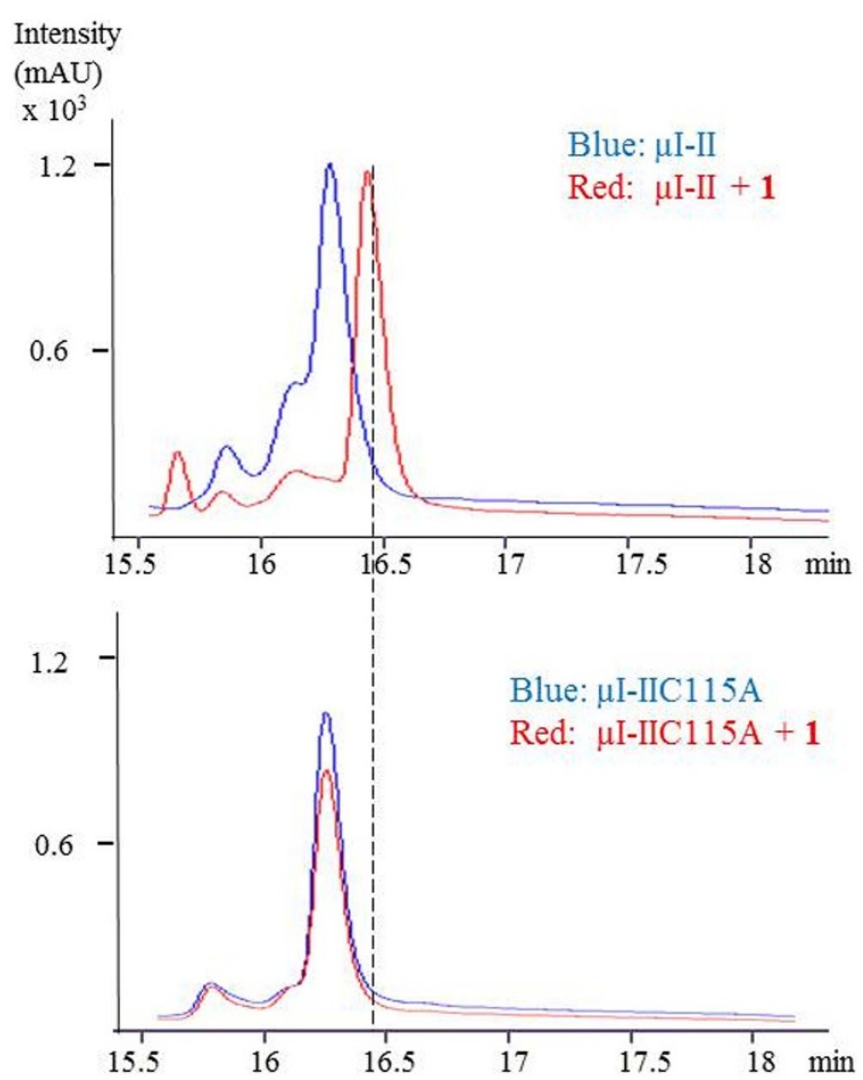

Figure $4 \mid$ HPLC comparison of $\mu \mathrm{I}-\mathrm{II}$ and $\mu \mathrm{I}$-IIC115A samples after the addition of 1 . The retention time of $\mu \mathrm{I}$-II was shifted by $0.3 \mathrm{~min}$, while no obvious shift can be observed in $\mu \mathrm{I}-\mathrm{IIC} 115 \mathrm{~A}$ sample.

Trypsin Digestion for Free HCAN1, HCAN1 + 1 and HCAN1 + 3 Samples. Trypsin (mass spectrometry grade, Promega) was added to the 3 samples for digestion to a final proteinase: protein ratio of $1: 50(\mathrm{w} / \mathrm{w})$ and incubated at $37^{\circ} \mathrm{C}$ for 24 hours. Digested samples were then desalted and purified using the C18 Zip Tip (Millipore), dissolved in saturated SA matrix solution, and analyzed in reflectron mode and linear mode by MALDI-TOF/TOF-MS.

Expression, Purification and Identification of $\mu \mathrm{I}-\mathrm{II}$ and $\mu \mathrm{I}-\mathrm{IIC} 115 \mathrm{~A}$. The cDNAs were obtained from $\mathrm{HeLa}$ cells by reverse transcription (SuperScript ${ }^{\circledR}$ III Reverse Transcriptase, Invitrogen ${ }^{\mathrm{TM}}$ ), and human $\mu \mathrm{I}$-II was amplified by PCR using $p f u$ DNA polymerase (Tiangen, China). The active site Cys115 was mutated to Ala by overlap PCR and confirmed by sequencing. The two DNA sequences were inserted into plasmid pet28a using BamHI and SalI, and the recombinant plasmids were sequenced and BLAST against human calpain 1 (see Supplementary Fig. 2).

$\mu \mathrm{I}-\mathrm{II}$ and $\mu \mathrm{I}-\mathrm{IIC} 115 \mathrm{~A}$ were expressed in E. coli BL21, and grown on LB medium containing $30 \mu \mathrm{g} / \mathrm{mL}$ kanamycin at $37^{\circ} \mathrm{C}$ with shaking (225 rpms). Protein expression was induced by the addition of $0.5 \mathrm{mM}$ IPTG at a bacterial concentration of $\mathrm{OD}_{600} 0.6$, followed by bacterial cell growth for an additional $18 \mathrm{~h}$ at $16^{\circ} \mathrm{C}$ before harvesting. Protein purification was conducted using $\mathrm{Ni}^{2+}$-affinity columns according to the manufacturer's instructions. Eluted protein was concentrated using a $30 \mathrm{~K}$ molecular weight filter and exchanged into storage buffer $(20 \mathrm{mM}$ imidazole- $\mathrm{HCl}$, $5 \mathrm{mM} \beta$-mercaptoethanol, 1 mM EDTA, 1 mM EGTA, 30\% glycol, $\mathrm{pH}$ 7.6).

The two expressed proteins were identified by SDS-PAGE and MS/MS annotation of trypsin digests. The map of SDS-PAGE showed that the molecular weight of two expressed proteins were $35-48 \mathrm{kDa}$ (see Supplementary Fig. 3), consistent with the predicted molecular weight. Tryptic peptides of $\mu \mathrm{I}-\mathrm{II}$ and $\mu \mathrm{I}$-IIC115A were analyzed by LC-HR-MS/MS using a Bruker Daltonics micrOTOF-QII. The tryptic peptide coverage of each protein, as determined by $\mathrm{MS}^{1}$ and verified by $\mathrm{MS}^{2}$, and the annotation of active site containing peptides are shown in Supplementary Fig. 4 and Fig. 5.

Intact Protein Sample Preparation and Analysis by FT-ICR-MS. In preparation for FT-ICR-MS analysis, the 4 proteins samples $(\mu \mathrm{I}-\mathrm{II}, \mu \mathrm{I}-\mathrm{II}+1, \mu \mathrm{I}-\mathrm{IIC} 115 \mathrm{~A}$, and $\mu \mathrm{I}-\mathrm{IIC} 115 \mathrm{~A}+1$ ) were purified by off-line HPLC (Agilent Infinity 1200 equipped with a multiple wavelength detector). Stock protein samples were thawed and then mixed with a $1 \mathrm{mM} \mathrm{CaCl}{ }_{2}$ solution. A portion of $\mu \mathrm{I}-\mathrm{II}$ and a portion of $\mu \mathrm{I}-\mathrm{IIC} 115 \mathrm{~A}$ were each mixed with a molar excess of $\mathbf{1}$ and these were allowed to incubate at room temperature for an additional 10 minutes prior to HPLC purification. Samples, each containing $10 \mu \mathrm{g}$ of protein, were injected onto a $\mathrm{C}_{4}$ RP-HPLC column (Jupiter $5 \mu \mathrm{C}_{4}, 150 \mathrm{~mm} \times 4.60 \mathrm{~mm}, 300 \AA$, Phenomenex). These samples were loaded at $1 \mathrm{ml} / \mathrm{min}$ of $90 \%$ mobile phase $\mathrm{A}\left(\mathrm{H}_{2} \mathrm{O}+0.1 \%\right.$ TFA) and $10 \%$ mobile phase $\mathrm{B}$ (ACN $+0.1 \%$ TFA), which was held for 5 minutes, then eluted by increasing to $90 \%$ mobile phase B over 20 minutes. Absorbance at $220 \mathrm{~nm}$ was monitored and fractions of the HPLC eluent containing the major peaks were collected, flash frozen, and lyophilized to dryness. Immediately prior to FT-ICR-MS analysis, lyophilized fractions were dissolved in $100 \mu \mathrm{l}$ of a solution containing a mixture of $49.5 \% \mathrm{H}_{2} \mathrm{O}, 49.5 \%$ methanol, and $1 \%$ formic acid (all LC/MS grade). Samples were introduced into an LTQ-FT hybrid mass spectrometer with a 6.4 T magnet (Thermo Electron, North America) using a TriVersa NanoMate (Advion BioSciences, Inc.). The NanoMate was utilized in direct-infusion mode with a spray pressure of $0.3 \mathrm{psig}$ and an ESI voltage of $1.4 \mathrm{kV}$. $\mu$ I-II sample

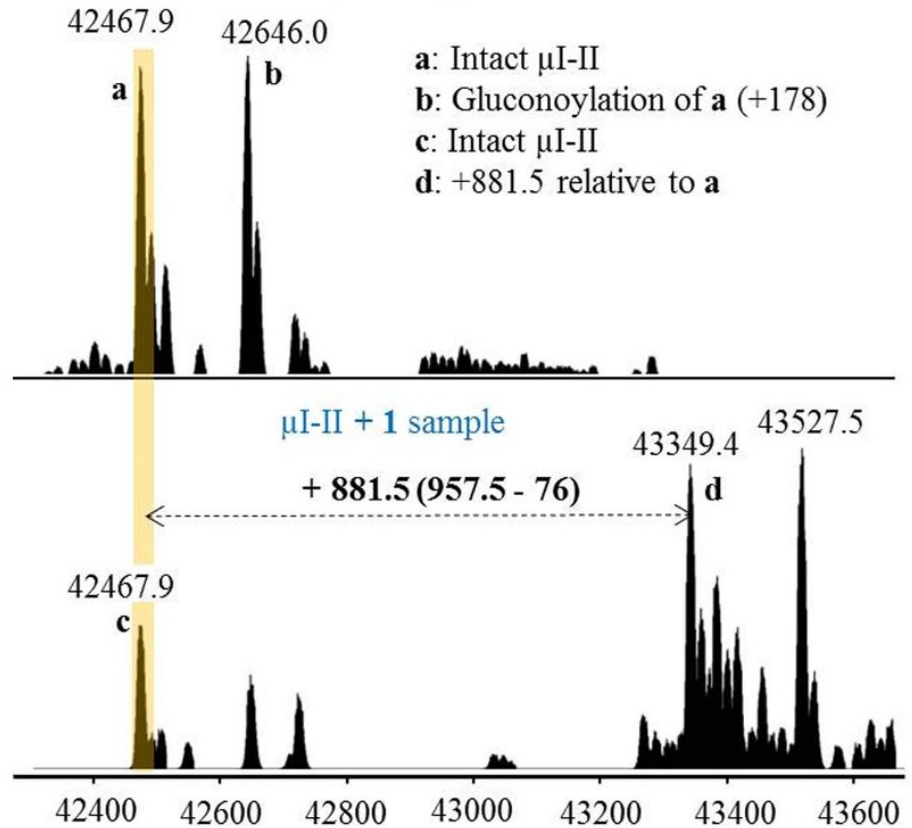

42360.1

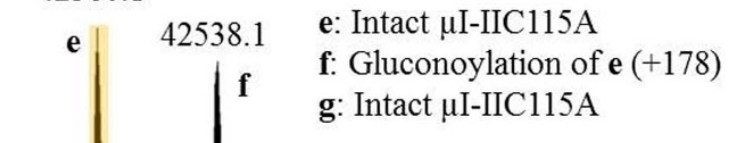

$\mu \mathrm{I}-\mathrm{IIC} 115 \mathrm{~A}$ sample

: Intact $\mu I-I I C 115 \mathrm{~A}$

g: Intact $\mu \mathrm{I}-\mathrm{IIC} 115 \mathrm{~A}$
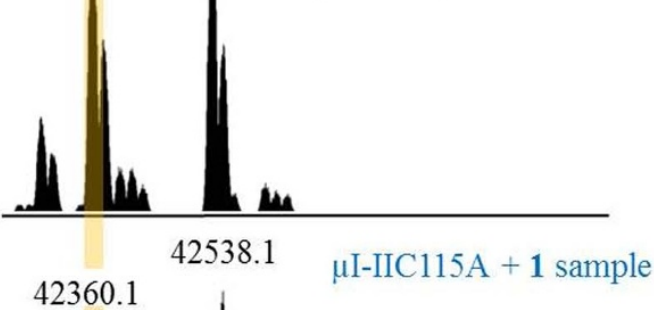

Figure 5 FT-ICR-MS analysis of $\mu \mathrm{I}-\mathrm{II}, \boldsymbol{\mu I}-\mathrm{II}+1, \boldsymbol{\mu I}-\mathrm{IIC115A}$, and $\boldsymbol{\mu I}$-IIC115A +1 . After the addition of $\mathbf{1}$, a 881.5 shift was clearly observed in $\mu \mathrm{I}-\mathrm{II}$ samples (peak a: 42467.9; peak d: 43349.4), while there was no shift in $\mu \mathrm{I}-\mathrm{IIC} 115 \mathrm{~A}$ samples (peak e: $42360.1 \mathrm{Da}$; peak g: $42360.1 \mathrm{Da}$ ). Mass spectra shown are deconvoluted with neutral monoisotopic masses displayed above each peak. 


\section{T D I $|\mathrm{C}| \mathrm{Q}|\mathrm{G}| \mathrm{A} \mid \mathrm{L}] \mathrm{G}] \mathrm{D}$ C W $|\mathrm{L}| \mathrm{L}|\mathrm{A}| \mathrm{A}|\mathrm{I}| \mathrm{A}|\mathrm{S}| \mathrm{L}|\mathrm{T}| \mathrm{L}|\mathrm{N}| \mathrm{D}|\mathrm{T}| \mathrm{L}|\mathrm{L}| \mathrm{H}$ R}

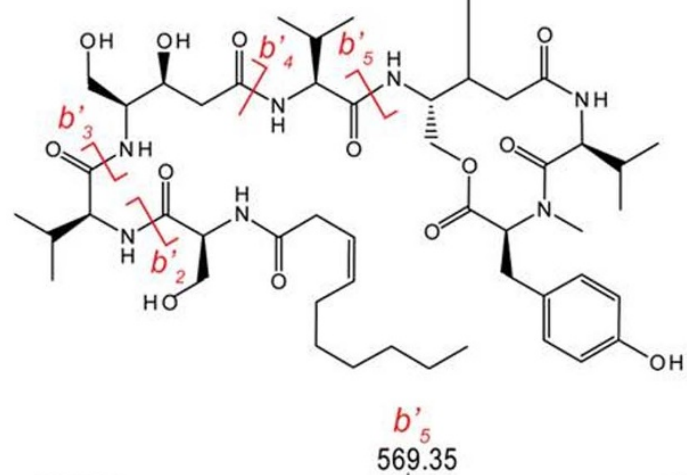
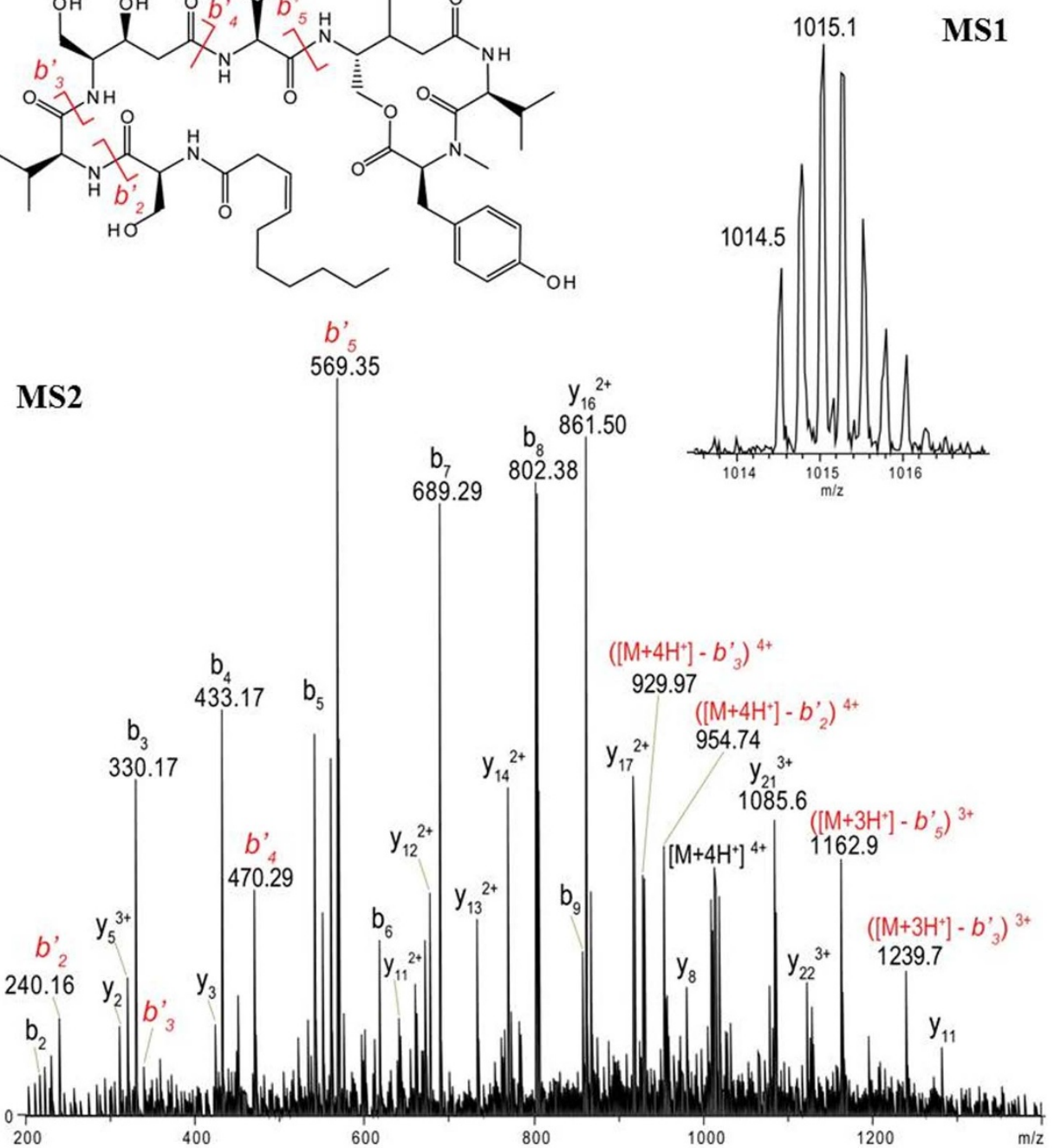

Figure $6 \mid$ MS/MS annotation of 1-modified fragment in the $\mu \mathrm{I}-\mathrm{II}+1$ sample (b ions of 1 labeled by $\boldsymbol{b}^{\prime}$ and red color).

The LTQ-FT ion optics were first tuned to $\mathrm{m} / \mathrm{z} 816$ using cytochrome C. The LTQ capillary temperature was maintained at $200^{\circ} \mathrm{C}$. For the acquisition of high-resolution FT-ICR-MS spectra of the intact protein samples the following settings were used: 200000 resolution, $\mathrm{m} / \mathrm{z}$ range of 700-1400, 3 micro-scans per scan, max injection time of $8000 \mathrm{~ms}$, and an FT automatic gain control (AGC) of 8 e5. In order to improve the clarity of the FT-ICR measurements of the intact proteins, an isolation window of $100 \mathrm{~m} / \mathrm{z}$ units was centered upon $\mathrm{m} / \mathrm{z} 1015$ in order to capture multiple charge states of the protein within each of the four samples, and a minimum of 1000 scans were acquired and averaged (see Supplementary Fig. 7). Deconvolution of intact protein FT-ICR mass spectra was performed by using Xtract (Thermo Electron, Bremen, Germany).

Limited Trypsin Digestion and FT-ICR-MS Analysis of $\mu \mathrm{I}$-II. A sample of protein $\mu \mathrm{I}$-II was briefly digested using trypsin (Trypsin Singles, proteomics grade, SigmaAldrich). A final trypsin:protein ratio of $1: 20(\mathrm{w} / \mathrm{w})$ was mixed and incubated at $37^{\circ} \mathrm{C}$ for 30 minutes in $40 \mathrm{mM}$ ammonium bicarbonate buffer. The reducing agents DTT and TCEP were intentionally excluding as these reducing agents have been shown to remove $\beta$-ME from the cysteines ${ }^{27}$. The limited trypsin digest of $\mu \mathrm{I}-\mathrm{II}$ was fractionated by HPLC using the same column and gradient that was utilized for the intact protein analysis. The eluent was collected in $1 \mathrm{ml}$ fractions (1 min/fraction), flash frozen, and lyophilized. The collected fractions were dissolved in $30-60 \mu \mathrm{L}$ of the $49.5 \% \mathrm{H}_{2} \mathrm{O}$, $49.5 \%$ methanol, and $1 \%$ formic acid mixture and analyzed by FT-MS using similar instrument parameters as previously outlined, with the exceptions being that the FTICR resolution was lowered to 50000 and the range of $\mathrm{m} / \mathrm{z} 200-2000$ was recorded for all fractions. Peptides were identified on the basis of their intact mass and $\beta$-ME modified peptides were verified by MS/MS fragmentation (see Supplementary Fig. 6).

Bottom-up Analysis of Protein Samples by LC-HR-MS/MS. In preparation for bottom-up analysis of the 4 proteins samples $(\mu \mathrm{I}-\mathrm{II}, \mu \mathrm{I}-\mathrm{II}+1, \mu \mathrm{I}-\mathrm{IIC} 115 \mathrm{~A}$, and $\mu \mathrm{I}-$
IIC115A + 1) each one was reduced with DTT, alkylated, and incubated with a trypsin: protein ration of $1: 20(\mathrm{w} / \mathrm{w})$ at $37^{\circ} \mathrm{C}$ for 18 hours. Samples were subsequently quenched with an equal volume of $10 \%$ formic acid. For LC-HR-MS/ MS analysis and Agilent Infinity 1290 UPLC connected to a Bruker Daltonics micrOTOF-QII qTOF mass spectrometer. The trypsin digested samples were separated using an RP-C ${ }_{18}$ column (Luna $3 \mu \mathrm{C}_{18}(2), 100 \mathrm{~mm} \times 2.0 \mathrm{~mm}, 100 \AA$ Phenomenex). Samples were loaded at $0.25 \mathrm{ml} / \mathrm{min}$ of $95 \%$ mobile phase A $(100 \%$ $\mathrm{H}_{2} \mathrm{O}+0.1 \%$ formic acid) and $5 \%$ mobile phase $\mathrm{B}(\mathrm{ACN}+0.1 \%$ formic acid), which was held for 3 minutes, then mobile phase $\mathrm{B}$ was increased to $65 \%$ over 30 minutes, and then B was increased to $100 \%$ over 2 minutes. The micrOTOF-QII was configured to have a nebulizer pressure of $1.6 \mathrm{bar}$, dry gas temperature of $200^{\circ} \mathrm{C}$, dry gas flow-rate of $7 \mathrm{~L} / \mathrm{min}$. Mass spectra were acquired with an $\mathrm{MS}^{1}$ spectral rate of $2 \mathrm{~Hz}$, an $\mathrm{MS}^{2}$ rate of $3 \mathrm{~Hz}$, and the collision RF was stepped from $200 \mathrm{Vpp}$ to $600 \mathrm{Vpp}$ (increments of $100 \mathrm{~V}$ ) during each $\mathrm{MS}^{2}$ event in order to maximize observed fragment ions. A "lock-mass" internal calibrant (m/z 922.01; CAS 58943-98-9) was continuously introduced into the mass spectrometer in order to maintain proper calibration throughout the run. The MS/MS annotation of thaA-modified peptide is detailed in Supplementary Fig. 8.

\section{Molecular Dynamics Simulations and Docking Study of Calpain and}

Thalassospiramides. The currently available structures for calpain-1 are 1ZCM and 2ARY, from which we selected the former because it is a bound structure in which the ligand is covalently linked to Cys $115^{28}$. To prepare the MD simulations, we removed the ligand and determined the protonation states of all histidines using the PDB2PQR server $^{41}$. The protein was then solvated in a water box with 13309 SPC waters $^{42}$ and 9 sodium ions to neutralize the system. The GROMACS 4.5.5 simulation package ${ }^{43}$ with the Amber99sb force field ${ }^{44}$ were used in the MD simulations due to their speed. The system was minimized with a steepest descent algorithm followed by $200 \mathrm{ps}$ MD simulations with a position restraint for heavy protein atoms, under NPT conditions 
with 1 bar of pressure and a temperature of $310 \mathrm{~K}$ using a V-rescale thermostat ${ }^{45}$. The cut-offs for both VDW and short-range electrostatic interactions were set at $10 \AA$, and long-range electrostatic interactions were treated according to the Particle-Mesh Ewald method ${ }^{46}$. Water molecules were constrained using the SETTLE algorithm ${ }^{47}$, and all protein bonds were constrained by the LINCS algorithm ${ }^{48}$. Finally, we performed three independent 50-ns NPT simulations with the same initial conformation (i.e., the last frame of the position restraint simulation) and different initial velocities. The conformations were saved every 5 ps.

All of the 30,000 MD simulation frames were collected and divided into 30 clusters according to the C-alpha of two flexible loops (residue 69-82 and 251-261) using the $\mathrm{k}$-center algorithm ${ }^{49}$. The average RMSD within each cluster was approximately $1.5 \AA$. We chose one representative conformation from each cluster for flexible docking using AutoDock Vina.

We used AutoDock Tools (ADT) to prepare the proteins and ligands prior to docking. The ADT merged nonpolar hydrogens of proteins and automatically detected each bond type of the ligands. Proteins and ligands were added with Gasteiger partial charges ${ }^{50}$. AutoDock Vina, which significantly improved the average accuracy of the binding mode prediction compared to AutoDock 4, was applied for the docking study. The docking grid box was centered near Cys 115 with a volume of $24 * 26 * 34\left(\mathrm{~A}^{3}\right)$, and each docking had 48 (parameter: exhaustive) parallel runs. The sequence index of the selected flexible residues was: $72,79,109,115,254,260,261,272$ and $298^{51}$.

Fluorescence-based 20S Proteasome Inhibition Assay. Thalassospiramide 1 and 4 were serially diluted in methanol to obtain various concentrations, and then incubated with $1 \mathrm{nM} 20 \mathrm{~S}$ proteasome in 96-well plates (Tris $25 \mathrm{mM}$, pH 7.5; SDS $0.03 \%$; EDTA $0.5 \mathrm{mM}$, final reaction volume $40 \mu \mathrm{L}$ ) for $15 \mathrm{~min}$ at $37^{\circ} \mathrm{C}$. The specific fluorogenic proteasome substrate Suc-LLVY-AMC $(10 \mu \mathrm{L}, 200 \mathrm{mM})$ was added and incubated for another $15 \mathrm{~min}$ at $37^{\circ} \mathrm{C}$, and then the fluorescence in each well was measured. The assay wells without inhibitor were conducted as positive control (related to $100 \%$ of enzyme activity) ${ }^{52}$.

Preliminary Toxicity Assays. The preliminary toxicity assays included antimicrobial and cytotoxic assays. In antimicrobial assay, LB (10 g of tryptone, $5 \mathrm{~g}$ of yeast extract, $10 \mathrm{~g}$ of $\mathrm{NaCl}, 1 \mathrm{~L}$ of dd $\mathrm{H}_{2} \mathrm{O}$ ) and potato dextrose medium ( $200 \mathrm{~g}$ of potato, $20 \mathrm{~g}$ of dextrose, $1 \mathrm{~L}$ of $\mathrm{dd}_{2} \mathrm{O}$ ) were used to inoculate strain $S$. aureus ATCC 43300 and $C$. albicans ATCC $76615\left(28^{\circ} \mathrm{C}\right.$, for $\left.12 \mathrm{~h}\right)$, respectively. The test samples were prepared at $1 \mathrm{mM}$ in DMSO and added to the broth (96-well plate) at $1 \%(\mathrm{~V} / \mathrm{V}$, final concentration $10 \mu \mathrm{M})$. Then, the microbes were incubated at $28^{\circ} \mathrm{C}$ overnight. Cell growth was recorded by measuring the optical density at $600 \mathrm{~nm}$, and Penicillin (for S. aureus) and Natamycin (for C. albicans) were used as positive controls. Human $\mathrm{HeLa}$ cells were used in cytotoxic assay. Cells $\left(80 \mu \mathrm{L}, 1 \times 10^{5} / \mathrm{mL}\right)$ were planted into 96-well plates for $12 \mathrm{~h}$, then the test samples were dissolved in DMSO and added to the assay medium to inoculate for another $48 \mathrm{~h}$. The cell viability was assayed by the MTT method.

1. Sorimachi, H., Hata, S. \& Ono, Y. Expanding members and roles of the calpain superfamily and their genetically modified animals. Exp. Anim. Tokyo 59, 549-566 (2010).

2. Saez, M. E., Ramirez-Lorca, R., Moron, F. J. \& Ruiz, A. The therapeutic potential of the calpain family: new aspects. Drug Discov. Today 11, 917-923 (2006).

3. Croall, D. E. \& Ersfeld, K. The calpains: modular designs and functional diversity. Genome Biol. 8, 11 (2007).

4. Saatman, K. E., Creed, J. \& Raghupathi, R. Calpain as a therapeutic target in raumatic brain injury. Neurotherapeutics 7, 31-42 (2010).

5. Zatz, M. \& Starling, A. Mechanisms of disease: calpains and disease. New Engl. J. Med. 352, 2413-2423 (2005).

6. Leloup, L. \& Wells, A. Calpains as potential anti-cancer targets. Expert Opin. Ther. Targets 15, 309-323 (2011).

7. Bevers, M. B. \& Neumar, R. W. Mechanistic role of calpains in postischemic neurodegeneration. J. Cereb. Blood Flow Metab. 28, 655-673 (2008).

8. Zadran, S., Bi, X. N. \& Baudry, M. Regulation of calpain-2 in neurons: implications for synaptic plasticity. Mol. Neurobiol. 42, 143-150 (2010).

9. Libertini, S. J. et al. Evidence for calpain-mediated androgen receptor cleavage as a mechanism for androgen independence. Cancer Res. 67, 9001-9005 (2007).

10. Pietsch, M., Chua, K. C. H. \& Abell, A. D. Calpains: Attractive targets for the development of synthetic inhibitors. Curr. Top. Med. Chem. 10, 270-293 (2010).

11. Cuerrier, D., Moldoveanu, T., Inoue, J., Davies, P. L. \& Campbell, R. L. Calpain inhibition by alpha-ketoamide and cyclic hemiacetal inhibitors revealed by X-ray crystallography. Biochemistry 45, 7446-7452 (2006).

12. Qian, J. et al. Cocrystal structures of primed side-extending alpha-ketoamide inhibitors reveal novel calpain-inhibitor aromatic interactions. J. Med. Chem. 51, 5264-5270 (2008).

13. Donkor, I. O. A survey of calpain inhibitors. Curr. Med. Chem. 7, 1171-1188 (2000).

14. Donkor, I. O. Calpain inhibitors: a survey of compounds reported in the patent and scientific literature. Expert Opin. Ther. Patents 21, 601-636 (2011).

15. Stuart, B. G. et al. Molecular modeling: A search for a calpain inhibitor as a new treatment for cataractogenesis. J. Med. Chem. 54, 7503-7522 (2011).
16. Schneck, J. L. et al. Chemical mechanism of a cysteine protease, cathepsin C, as revealed by integration of both steady-state and pre-steady-state solvent kinetic isotope effects. Biochemistry 47, 8697-8710 (2008).

17. Ross, A. C. et al. Biosynthetic multitasking facilitates thalassospiramide structural diversity in marine bacteria. J. Am. Chem. Soc. 135, 1155-1162 (2013).

18. Groll, M. et al. A plant pathogen virulence factor inhibits the eukaryotic proteasome by a novel mechanism. Nature 452, 755-U7 (2008).

19. Shiraki, T. et al. Alpha, beta-unsaturated ketone is a core moiety of natural ligands for covalent binding to peroxisome proliferator-activated receptor. J. Biol. Chem. 280, 14145-14153 (2005).

20. Reverdy, C. et al. Discovery of specific inhibitors of human USP7/HAUSP deubiquitinating enzyme. Chem. Biol. 19, 467-477 (2012).

21. Ge, Y., Rybakova, I. N., Xu, Q. G. \& Moss, R. L. Top-down high-resolution mass spectrometry of cardiac myosin binding protein $\mathrm{C}$ revealed that truncation alters protein phosphorylation state. Proc. Natl. Acad. Sci. U.S.A. 106, 12658-12663 (2009).

22. Zhang, J. A., Dong, X. T., Hacker, T. A. \& Ge, Y. Deciphering modifications in swine cardiac troponin I by top-down high-resolution tandem mass spectrometry. J. Am. Soc. Mass Spectrom. 21, 940-948 (2010).

23. Paul, B., Das, D., Ellington, B. \& Marsh, E. N. G. Probing the mechanism of cyanobacterial aldehyde decarbonylase using a cyclopropyl aldehyde. J. Am. Chem. Soc. 135, 5234-5237 (2013).

24. Chait, B. T. Mass spectrometry: Bottom-up or top-down? Science 314, 65-66 (2006).

25. Moldoveanu, T. et al. $\mathrm{A} \mathrm{Ca}^{2+}$ switch aligns the active site of calpain. Cell $\mathbf{1 0 8}$ 649-660 (2002)

26. Orsatti, L., Pallaoro, M., Steinkuler, C., Orru, S. \& Bonelli, F. Reactivity of the NS2/ $3((907-1206))$ ASK(4) protein with beta-mercaptoethanol studied by electrospray ion trap mass spectrometry. Rapid Commun. Mass Spectrom. 16, 1919-1927 (2002).

27. Begg, G. E. \& Speicher, D. W. Mass spectrometry detection and reduction of disulfide adducts between reducing agents and recombinant proteins with highly reactive cysteines. J. Biomol. Tech. 10, 17-20 (1999).

28. Li, Q. S., Hanzlik, R. P., Weaver, R. F. \& Schonbrunn, E. Molecular mode of action of a covalently inhibiting peptidomimetic on the human calpain protease core. Biochemistry 45, 701-708 (2006).

29. Clerc, J. et al. Synthetic and structural studies on syringolin A and B reveal critical determinants of selectivity and potency of proteasome inhibition. Proc. Natl. Acad. Sci. U.S.A. 106, 6507-6512 (2009).

30. Mertens, M. D. et al. A coumarin- labeled vinyl sulfone as tripeptidomimetic activity- based probe for cysteine cathepsins. ChemBioChem 15, 955-959 (2014)

31. Kaneko, I. et al. inventors; Sankyo Co., Ltd. assignee. New compound B1371A or B1371B and their production. Japanese patent JP 06,298,796 (A). 1994 Oct 25.

32. Osumi, H. et al. inventors; Sankyo Co., Ltd. assignee. New compound B1371E or B1371F and their production. Japanese patent JP 08,081,431 (A). 1996 Jun 23.

33. Um, S. et al. Thalassospiramide G, a new gamma-amino-acid-bearing peptide from the marine bacterium Thalassospira sp. Mar. Drugs 11, 611-622 (2013).

34. Kang, D. H. et al. Identification of 3-Acetyl-2-aminoquinolin-4-one as a novel, nonpeptidic scaffold for specific calpain inhibitory activity. J. Med. Chem. 52, 3093-3097 (2009).

35. Cuerrier, D. et al. Development of calpain-specific inactivators by screening of positional scanning epoxide libraries. J. Biol. Chem. 282, 9600-9611 (2007).

36. Shirasaki, Y. et al. Exploration of orally available calpain inhibitors 2: Peptidyl hemiacetal derivatives. J. Med. Chem. 49, 3926-3932 (2006).

37. Donkor, I. O., Assefa, H. \& Liu, J. Structural basis for the potent calpain inhibitory activity of peptidyl alpha-ketoacids. J. Med. Chem. 51, 4346-4350 (2008).

38. Ettari, R. et al. Novel peptidomimetics containing a vinyl ester moiety as highly potent and selective falcipain-2 Inhibitors. J. Med. Chem. 52, 2157-2160 (2009)

39. Kathman, S. G., Xu, Z. \& Statsyuk, A. V. A Fragment-based method to discover irreversible covalent inhibitors of cysteine proteases. J. Med. Chem. 57, 4969-4974 (2014).

40. Nonoo, R. H., Armstrong, A. \& Mann, D. J. Kinetic template-guided tethering of fragments. Chemmedchem 7, 2082-2086 (2012).

41. Dolinsky, T. J., Nielsen, J. E., McCammon, J. A. \& Baker, N. A. PDB2PQR: An automated pipeline for the setup of Poisson-Boltzmann electrostatics calculations. Nucleic Acids Res. 32 (Web Server issue) W665-7 (2004).

42. Berendsen, H. J. C., Grigera, J. R. \& Straatsma, T. P. The missing term in effective pair potentials. J. Phys. Chem.-Us 91, 6269-6271 (1987).

43. Hess, B., Kutzner, C., van der Spoel, D. \& Lindahl, E. GROMACS 4: Algorithms for highly efficient, load-balanced, and scalable molecular simulation. J. Chem. Theory Comput. 4, 435-447 (2008).

44. Hornak, V. et al. Comparison of multiple amber force fields and development of improved protein backbone parameters. Proteins 65, 712-25 (2006).

45. Berendsen, H. J. C., Postma, J. P. M., Vangunsteren, W. F., Dinola, A. \& Haak, J. R. Molecular-dynamics with coupling to an external bath. J. Chem. Phys. 81, 3684-3690 (1984)

46. Cerutti, D. S., Duke, R. E., Darden, T. A., \& Lybrand, T. P. Staggered mesh ewald: An extension of the smooth particle-mesh ewald method adding great versatility. J. Chem. Theory Comput. 5, 2322-2338 (2009).

47. Miyamoto, S. \& Kollman, P. A. Settle - an analytical version of the shake and rattle algorithm for rigid water models. J. Comput. Chem. 13, 952-962 (1992). 
48. Hess, B., Bekker, H., Berendsen, H. J. C., Fraaije, J. G. E. M. LINCS: A linear constraint solver for molecular simulations. J. Comput. Chem. 18, 1463-1472 (1997).

49. Bowman, G. R., Huang, X. H. \& Pande, V. S. Network models for molecular kinetics and their initial applications to human health. Cell Res. 20, 622-630 (2010).

50. Morris, G. M. et al. AutoDock 4 and AutoDock Tools 4: automated docking with selective receptor flexibility. J. Comput. Chem. 30, 2785-2791 (2009).

51. Trott, O. \& Olson, A. J. Software news and update AutoDock Vina: Improving the speed and accuracy of docking with a new scoring function, efficient optimization, and multithreading. J. Comput. Chem. 31, 455-461 (2010).

52. Trivella, D. B. B. et al. Enzyme inhibition by hydroamination: Design and mechanism of a hybrid carmaphycin-syringolin enone proteasome inhibitor. Chem. Biol 21, 782-791 (2014).

\section{Acknowledgments}

The authors thank Dr. Jianwei Sun for discussions regarding the structural chemistry, Dr. Peggy Pai, Miss Xiaofen Liu and Miss Joyce Wong for technical assistance with the MALDI-TOF-MS, Dr. Daniela B.B. Trivella for 20 S proteasome inhibition assay, and HKUST Biosciences Central Research Facility for providing MS services. The work was supported by grants from the China Ocean Mineral Resources Research and Development Association (DY125-15-T-02), the King Abdullah University of Science and Technology
(SA-C0040/UK-C0016), the National Natural Science Foundation of China (21273188), and the NIH (GM97509).

\section{Author contributions}

L.L., M.M., Z.C., X.H., P.D., Y.X., B.M. and P.Q. designed the experiments, L.L, M.M., S.G., W.Z., G.Z., L.L.(IU). executed the experiments, L.L., M.M., S.G. analyzed data and prepared the figures, and L.L. wrote the manuscript with the input from all authors.

\section{Additional information}

Supplementary information accompanies this paper at http://www.nature.com/ scientificreports

Competing financial interests: The authors declare no competing financial interests

How to cite this article: Lu, L. et al. Mechanism of Action of Thalassospiramides, A New Class of Calpain Inhibitors. Sci. Rep. 5, 8783; DOI:10.1038/srep08783 (2015).

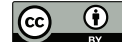

This work is licensed under a Creative Commons Attribution 4.0 International License. The images or other third party material in this article are included in the article's Creative Commons license, unless indicated otherwise in the credit line; if the material is not included under the Creative Commons license, users will need to obtain permission from the license holder in order to reproduce the material. To view a copy of this license, visit http://creativecommons.org/licenses/by/4.0/ 